\title{
Adjustment Disorder
}

National Cancer Institute

\section{Source}

National Cancer Institute. Adjustment Disorder. NCI Thesaurus. Code C92191.

A category of psychiatric disorders which are characterized by emotional or behavioral symptoms that develop within 3 months of a stressor and do not persist for more than an additional 6 months after the stressor is no longer present. 